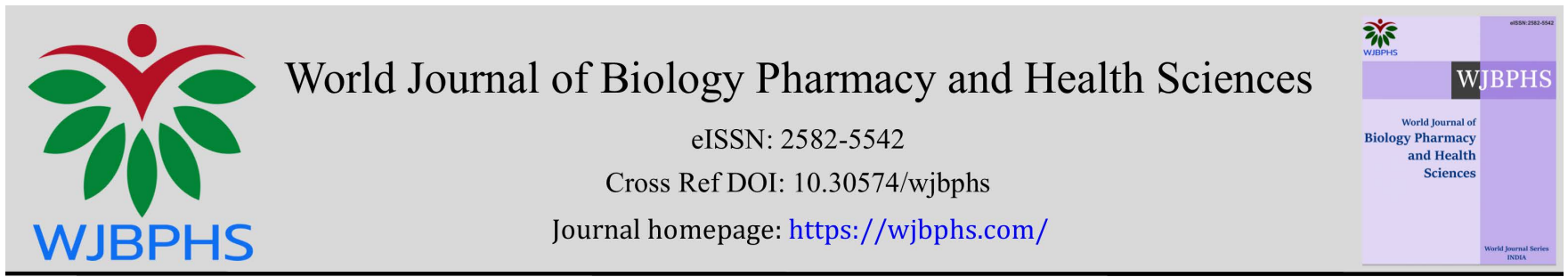

(RESEARCH ARTiCLE)

\title{
Does surface treatment of demineralized dentin impact on shear bond strength?
}

\author{
Fatemeh Rezaei ${ }^{1}$, Atefeh Nemati-Karimooy ${ }^{2}$, Horieh Moosavi 2,* \\ ${ }^{1}$ I.M.Sechenova Medical Institute, Moscow, Russia. \\ 2 Department of Restorative and Cosmetic Dentistry, School of Dentistry, Mashhad University of Medical Sciences, Dental \\ Research Center, Mashhad University of Medical Sciences, Iran.
}

World Journal of Biology Pharmacy and Health Sciences, 2021, 06(02), 023-028

Publication history: Received on 03 April 2021; revised on 08 May 2021; accepted on 11 May 2021

Article DOI: https://doi.org/10.30574/wjbphs.2021.6.2.0045

\begin{abstract}
Aim: This study investigated the effect of various surface treatments on the bond strength of a universal adhesive to demineralized dentin.

Materials and Methods: Human dentin surfaces of forty-eight carries-free maxillary premolars were prepared and demineralized by acidic solutions. Teeth were randomly distributed into four groups $(n=12)$ getting different surface treatments. Three minutes application of a CPP-ACP (group 1), Er: YAG laser irradiation (group 2), Er: YAG laser irradiation combined with three minutes application of CPP-ACP (group 3), no treatment (group 4). Thereafter composite tube (Filtek TM Ultimate, 3M ESPE) bonded to the testing surfaces via universal adhesive; Single Bond Universal and the Shear Bond Strength (SBS) measured. Data were analyzed utilizing ANOVA and Tukey tests $(\mathrm{P}<0.05)$.

Results: Only application of CPP-ACP and Er: YAG laser radiation, resulted in the highest and lowest SBS respectively $(\mathrm{p}<0.001)$. Bond strength after irradiation of Er: YAG laser combined with three minutes application of CPP-ACP was a little more than laser alone.
\end{abstract}

Conclusion: The application of CPP-ACP could increase the SBS of universal adhesives used to demineralized dentin. Laser irradiation application has an adverse effect on SBS.

Keywords: CPP-ACP; Demineralized dentin; Er:YAG laser; Shear bond strength

\section{Introduction}

Recently, developments in the field of adhesive dentistry have made numbers of changes in cavity preparations. In the sequence of tooth preparation, it is desirable removing only infected dentin, leaving affected that may be remineralizable dentin. Albeit this influenced dentin has an unblemished collagen grid and no microscopic organisms, its mineral substance has marked down which brought about lower bond strength costs than typical dentin. [1]

Since the suitable bonding of tooth-colored materials to the tooth structure has a primary impact in the durability and viability of direct composite rebuilding efforts, strategies that lead to expanded bond strength have consistently been considered. These days, laser illumination is another innovation in treatment of dental caries. [2] In most recent years, various types of lasers were evaluated either for restraint or capturing tooth caries. [2-4] Laser treatment of dental hard tissues can reason various levels of organic or morphological changes, which relies upon retention highlights of the tissue and the sort of laser and its boundaries. [5]

\footnotetext{
${ }^{*}$ Corresponding author: Horieh Moosavi

Department of Restorative and Cosmetic Dentistry, School of Dentistry, Mashhad University of Medical Sciences, Dental Materials Research Center, Mashhad University of Medical Sciences, Iran. Tel: 00985138829504; E-mail: moosavih@mums.ac.ir 
However, different investigations which have been evaluated the impact of laser radiation on bond strength, has indicated an exceptionally opposing outcomes. The sort and boundaries of the laser, the kind of dental substrate, the applied adhesive system and even the test used to assess the bond strength, all are compelling elements. [6-8]

On the other hand, a few specialists accept that the utilization of calcium-phosphor syntheses, for example, CPP-ACP containing paste on demineralized dentin may improve bond strength by components, for example, connection with MDP monomers of cements or expanding $\mathrm{pH} .[9,10]$

All things considered, restricted examinations have assessed the result of the synchronous use of Er: YAG laser illumination and CPP-ACP containing paste application on bond solidarity to demineralized dentin.

Along these lines, our point in this in vitro study was to research the impact of Er: YAG laser radiation and the utilization of CPP-ACP containing paste (MI Paste) on the shear bond strength of universal adhesives with self-etch mode to demineralized dentin

The null hypothesis of this examination was that there is no critical distinction in the SBS with or without various treatments.

\section{Material and methods}

Human dentin surfaces of forty-eight carries-free maxillary premolars were extracted for orthodontic aims were designated under a protocol permitted by the Ethics Committee of Mashhad University of Medical Sciences (IR.mums.sd.REC.1394.196). The teeth were kept in $0.5 \%$ thymol arrangement at $48^{\circ} \mathrm{C}$ and utilized inside one month of extraction. The entirety of the occlusal enamel was removed utilizing a water-cooled low-speed diamond saw. The accuracy of enamel removal was tested utilizing a stereomicroscope (Dino lite Pro, Anmo Electronics Corp, Taiwan) by $10 \times$ magnification.

The teeth mounted in pink acrylic resin utilizing tiny plastic cylinders, with the goal that a flat dentin surface opposite to the long pivot of the tooth accomplished.

The uncovered dentin was refined with 400 to 1200 coarseness SiC paper for 60 s under running water. To assemble fake caries-affected dentin lesions, all the examples were exposed to a pH-cycling technique.

The demineralizing solution confined $2.2 \mathrm{mM} \mathrm{NaH}_{2} \mathrm{PO}_{4}, 2.2 \mathrm{mM} \mathrm{CaCl}_{2}$, and $50 \mathrm{mM}$ acetic acid, adjusted to pH 4.8, and the remineralization solution tested $0.9 \mathrm{mM} \mathrm{NaH}_{2} \mathrm{PO}_{4}, 1.5 \mathrm{mM} \mathrm{CaCl}_{2}$, and $0.15 \mathrm{mM} \mathrm{KCl}$, adjusted to $\mathrm{pH} 7.0$.

During 14 days, each example was cycled at room temperature for eight hours in $10 \mathrm{ml}$ of demineralizing arrangement and afterward for 16 hours in remineralizing arrangement. The arrangements were reestablished every day. [11]

The dentin surfaces were tried under $50 \mathrm{~g}$ loads for $10 \mathrm{~s}$ with a micro-Vickers hardness analyzer (MH3 model, Koopaco, Iran) to check the demineralization interaction.

Three estimations were accomplished for each example and the normal of them was noted as surface hardness.

Teeth were randomly distributed into four groups $(\mathrm{n}=12)$ and getting different surface treatments.

- Group 1: CPP-ACP containing cream (MI Paste, GC, and Japan) was applied on dentin surface for three minutes, then, the surfaces were cleaned with a wet napkin.

- Group 2: the dentin surface was irradiated with Er: YAG dental laser (Pluser, LAMBDA SPA, Italy) with spot size of $1 \mathrm{~mm}$, wavelength of $2940 \mathrm{~nm}$, power of $0.40 \mathrm{~W}$, frequency of $10 \mathrm{~Hz}$, and energy output of $40 \mathrm{~mJ}$. The laser was applied using a light painting technique for $30 \mathrm{~s}$ with the beam focused perpendicular to the dentin surface from $5 \mathrm{~mm}$ space with $0 \%$ water and $0 \%$ air.

- Group 3: the Er: YAG laser with the same parameters of group 2 was irradiated to the surface for $30 \mathrm{~s}$, while the CPP-ACP containing cream was in place for three minutes.

- Group 4 (control group): The specimens of this group received no treatment.

The Single Bond Universal adhesive (3M Deutschland GmbH, Germany) applied to the surface for 20s with light brushing motion, air thinned 5s and light cured 10s with LED Curing Light (JR-CL37 Foshan SCS Medical Instrument Co., Ltd, 
China). Cylinder-shaped $3 \times 4 \mathrm{~mm}$ tygon tubes were located on the surface of the samples, filled with composite resin; Filtek $^{\mathrm{TM}}$ Ultimate, A2 Dentin shade (3M ESPE, Dental Products USA) via layering technique and light cured with an intensity of $1200 \mathrm{~mW} / \mathrm{cm} 2$ for $40 \mathrm{~s}$. All the specimens were put away in tap water at $37^{\circ} \mathrm{C}$ for one day, and thermocycled for 1000 cycles somewhere in the range of 5 and $55^{\circ} \mathrm{C}$, with a stay season of $30 \mathrm{sec}$ each (SANTAM Iran, SANTAM - STM zo). Then shear testing was directed by means of a universal testing machine (Model DBBP50, BONGSHIN LOADCELL CO., LTD, Korea) with a crosshead speed of $1 \mathrm{~mm} / \mathrm{min}$. Fractured samples were examined by a stereomicroscope for observation of the failure type, which were categorized as cohesive, adhesive, or mixed. [12]

\section{Statistical Analysis}

Data normality was assessed using Shapiro-Wilk test. Comparison of SBS values were done by one-way analysis of variance test followed by Tukey test. Significances were set at the 0.05 possibility level.

\section{Results}

The SBS information is appeared in Table 1. The use of CPP-ACP only, brought about the most elevated SBS, while the least SBS was seen in the group of Er: YAG laser radiation $(\mathrm{P}<0.001)$. One-way ANOVA showed significant differences in the mean SBS among four tested groups $(P<0.05)$. The SBS after irradiation of Er: YAG laser combined with three minutes application of CPP-ACP was more than laser alone, but both of them were significantly lower than that of untreated demineralized dentin. Moreover, laser illumination with and without CPP-ACP application has a significantly unfavorable impact on SBS of reinforced demineralized dentin in correlation of untreated demineralized dentin. Pairwise assessment demonstrated noteworthy contrasts among four groups $(\mathrm{p}<0.001)$. Likewise, failure mode appropriations are presented in Table 2. The highest (92\%) and lowest (42\%) of adhesive failure percentage were belong to the highest and lowest SBS groups respectively.

Table 1 Mean \pm SD of shear bond strength in all groups

\begin{tabular}{|l|l|}
\hline Group & Mean \pm SD \\
\hline 1: MI Paste & $32.85 \pm 3.80^{\mathrm{a}}$ \\
\hline 2: Laser & $13.37 \pm 2.12^{\mathrm{b}}$ \\
\hline 3: Laser+ MI Paste & $19.27 \pm 1.40^{\mathrm{c}}$ \\
\hline 4: Control & $22.87 \pm 2.82 \mathrm{~d}$ \\
\hline
\end{tabular}

Table 2 Failure mode percentages after shear bond strength test for each treatment group

\begin{tabular}{|l|l|l|l|}
\hline Experimental group & Cohesive & Adhesive & Mixed \\
\hline 1: MI Paste & $3(25 \%)$ & $5(42 \%)$ & $4(33 \%)$ \\
\hline 2: Laser & $0(0 \%)$ & $11(92 \%)$ & $1(8 \%)$ \\
\hline 3: Laser+ MI Paste & $0(0 \%)$ & $10(83 \%)$ & $2(17 \%)$ \\
\hline 4: Control & $1(8 \%)$ & $8(67 \%)$ & $3(25 \%)$ \\
\hline
\end{tabular}

\section{Discussion}

In spite of the importance of conservative dentistry in the current century, there are not many investigations in the field of strengthening the demineralized dentin. In this investigation, application of CPP-ACP, and lead to the highest SBS, while the lowest SBS was detected in the group which the Er: YAG laser radiation on demineralized dentin was the only therapy formerly bonding procedure. Therefore, our results did not support the null hypothesis. Owing to the difficulty in homogenization of dental models with ordinary caries, a demineralizing solution was prepared in this in vitro study, established on the prior research. [11] CPP-ACP is an effective remineralizing agent. Already, an examination 
demonstrated that the utilization of a CPP-ACP compound before the use of self-etch adhesive systems could increase the SBS of some self-etch adhesives by influencing the morphology of the dentin-resin interface. These findings are partially steady with the present study. $[9,13]$ However some authors accept that applying CPP-ACP before the bonding practice may be proficient to bargain the bond strength because of dentin tubules obliteration, staying away from bond penetration all through the collagen fibrils. $[14,15]$ It is additionally expressed that as MI Paste isn't pure CPP-ACP, the presence of different segments in the MI Paste other than CPP-ACP, which is the target of most investigations, could negatively affect bond strength. [16] In the current investigation, it was applied a universal adhesive in self-etch mode. The fact is that the bonding mechanism of self-etch and total-etch adhesives is actual various. One of the advantages of self-etch adhesives is their capacity of incorporating the smear layer and turning into a piece of the cross hybrid layer. Therefore, the additional components of the paste are probably considered as debris and have not interfered with the bond. [16] Moreover, this hybridized smear layer can extend the module of elasticity of the hybrid layer, thus, the bond strength of adhesive systems with lower conditioning power increases. [17] In addition, since self-etching adhesive systems only cause partial demineralization of dental tissue, residual dentin minerals may be effective in bond quality in the presence of functional monomers in adhesive. The study by Yoshida et al. revealed that the interaction of MDP monomers in universal self-etch adhesives with calcium and phosphate deposited on dentin following the application of CPP-ACP, creates a stable calcium-monomer salt which increases the bond strength to dentin. [18] On the other hand, calcium phosphate in CPP-ACP, can increase $\mathrm{pH}$. It has been shown that mild self-etch adhesives with higher $\mathrm{pH}$, cause better bond strength to dentin. [19] However, in the study we used adhesive with $\mathrm{pH}=1.5$. In a previous study, the effect of composition containing CPP-ACP and fluoride on the bond strength of adhesives to dentin in permanent teeth was assessed and no significant difference was observed in SBS. [20] In one investigation, subsequent the utilization of both etch \& rinse and self-etch adhesives, no critical change was seen on the SBS after the use of the fluoride free CPP-ACPcontaining compound, yet the compound containing the fluoridated CPP-ACP as a pretreatment, diminished the SBS. [21] The consequences of these investigations were in opposition to those found in the current study which may be because of the presence of fluoride in a portion of the compositions and use of various bonding materials and conventions. In the current study, Er: YAG laser was illuminated from the 5-mm space of the demineralized dentin surface in short rhythm mode with the wavelength of $2940 \mathrm{~nm}$, rate of $10 \mathrm{~Hz}$, power of $0.40 \mathrm{w}$, and energy of $40 \mathrm{~mJ}$ with no air and water as a round movement for $30 \mathrm{~s}$. Since Er: YAG laser has a low entrance profundity, there is no danger to the pulp and tissue around the teeth. [22]

The utilization of such attributes of laser radiation on dentin surface in this investigation lessened the SBS. Ceballo also expressed that laser may diminish the bond strength since dentin removal fuses collagen fibrils and diminishes interfibrillar spaces bringing about resulting decrease in resin dispersion into inter-tubular spaces and therefore less inter-tubular maintenance. [23] It appears to be that decrease of bond strength in the laser group in the current research can be because of initially the damage of dentin organic elements and changes in surface morphology of the tooth, trailed by decrease of calcium and phosphate in dentinal substrate and alterations in the arrangement of hydroxyapatite.

It is supposed that subsequently Er: YAG laser radiation, the temperature quickly rises in the irradiated surfaces, and because of the great absorption range of Er: YAG in water and hydroxyapatite, the captivated energy in the surface layer consequences in degradation of the surface layer. [5]

Several researches suggested that laser with the capability of hard tissue ablation, if used simultaneously with fluoride compositions, could raise the penetration of ions into minor seats in the enamel and dentin. Moreover, laser heat can produce well cracks and small spaces that help fluoride diffusion. [24,25,26]

However, in the current examination, the SBS esteems diminished fundamentally after the synchronous utilization of MI-paste and laser.

The discoveries of this investigation show that albeit the utilization of MI Paste can rise the SBS of the dentin, however when applied with the Er: YAG laser at the same time, its impact isn't sufficient for neutralizing the dangerous impacts of the laser on bond strength. The findings of Kamozaki et al. were like the results of this experiment, so the radiation of laser on mellowed dentin surfaces decreased bond strength following the utilization of self-etch adhesive, and the blend utilization of laser and MI Paste didn't improve the bond strength in contrast with not utilizing extra therapies. [13] The consequences of this investigation affirmed that in groups with highest bond strength (MI past treatment), fewer adhesive and more mix or cohesive failures were occurred, and in groups with inferior bond strength (laser plus MI paste), failures were more adhesive.

Like our outcomes, in a past report, the microtensile bond strength values assessed in in groups illuminated with Er: YAG laser, was low and failure mode was more adhesive. [27] 
One of the restrictions of this examination was the utilization of just one adhesive. Since various adhesives may show various practices, contingent upon the synthesis and convention of utilization, the in-vitro and in-vivo long-term water storage investigations of different adhesives in future can give further generalizability and more clear outcomes.

\section{Conclusion}

Within the limitations of the investigation, it tends to be determined that the application of CPP-ACP can increase the SBS of universal adhesives used in self-etch mode to demineralized dentin. Furthermore, Laser irradiation application has no positive effect on SBS.

\section{Compliance with ethical standards}

\section{Acknowledgments}

We thank the Vice-Chancellery of Research, Mashhad University of Medical Sciences, for supporting this research and Dental Materials Research Center of Mashhad University of Medical Sciences for testing the specimens (Number:950862).

\section{Disclosure of conflict of interest}

There are no conflicts of interest.

\section{References}

[1] Zanchi CH, Guerra Lund R, Perrone LR, Ribeiro GA, del Pino FB, Pinto MB, et al. Microtensile bond strengrth of two-step etch-and-rinse adhesive systems on sound and artificial caries-affected dentin. Am J Dent. 2010; 23: 152-156.

[2] Mei ML, Chu CH, Low KH, Che CM, Lo EC. Caries arresting effect of silver diamine fluoride on dentine carious lesion with S. mutans and L. acidophilus dual-species cariogenic biofilm. Med Oral Patol Oral Cir Bucal. 2013; 18: e824-831.

[3] Chin-Ying SH, Xiaoli G, Jisheng P, Wefel JS. Effects of CO 2 laser on fluoride uptake in enamel. J Dent. 2004; 32: 161-167.

[4] Ana P, Tabchoury C, Cury J, Zezell D. Effect of Er, Cr: YSGG laser and professional fluoride application on enamel demineralization and on fluoride retention. Cari Res. 2012; 46: 441-451.

[5] Moosavi H, Ghorbanzadeh S, Ahrari F. Structural and Morphological Changes in Human Dentin after Ablative and Subablative Er: YAG Laser Irradiation. J Lasers Med Sci. 2016; 7: 86-891.

[6] Bader C, Krejci I. Indications and limitations of Er: YAG laser applications in dentistry. Ame J Dent. 2006; 19: 178186.

[7] Koliniotou-Koumpia E, Kouros P, Zafiriadis L, Koumpia E, Dionysopoulos P, Karagiannis V. Bonding of adhesives to Er: YAG laser-treated dentin. Eur J Dent. 2012; 6: 16-22.

[8] Shahabi S, Chiniforush N, Bahramian H, Monzavi A, Baghalian A, Kharazifard MJ. The effect of erbium family laser on tensile bond strength of composite to dentin in comparison with conventional method. Lase Med Sci. 2013; 28: 139-142.

[9] Borges BCD, Souza-Junior EJ, da Costa GdFA, Pinheiro IVdA, Sinhoreti MAC, Braz R, et al. Effect of dentin pretreatment with a casein phosphopeptide-amorphous calcium phosphate (CPP-ACP) paste on dentin bond strength in tridimensional cavities. Acta Odont Scand. 2013; 71: 271-277.

[10] Atomura J, Inoue G, Nikaido T, Yamanaka K, Uo M, Tagami J. Influence of FCP-COMPLEX on bond strength and the adhesive-artificial cariesaffected dentin interface. Dent Mater J. 2018; 37: 775-782.

[11] Kucukyilmaz E, Savas S, Akcay M, Bolukbasi B. Effect of silver diamine fluoride and ammonium hexafluorosilicate applications with and without Er: YAG laser irradiation on the microtensile bond strength in sound and cariesaffected dentin. Lase Surg Med. 2016; 48: 62-69.

[12] Versluis A, Tantbirojn D, Douglas W. Why do shear bond tests pull out dentin? J Dent Res. 1997; 76: $1298-1307$. 
[13] Kamozaki MBB, Prakki A, Perote LCCC, Gutierrez NC, Pagani C. The effect of CPP-ACP and Nd: YAG laser on the bond strength of softened dentin. Braz Oral Res. 2015; 29: 1-7.

[14] Adebayo 0, Burrow M, Tyas M. Dentine bonding after CPP-ACP paste treatment with and without conditioning. J Dent. 2008; 36: 1013-1024.

[15] Adebayo 0, Burrow M, Tyas M. Resin-dentine interfacial morphology following CPP-ACP treatment. J Dent. 2010; 38: 96-105.

[16] Santos RAd, de Lima EA, Montes MAJR, Braz R. Pre-treating dentin with chlorhexadine and CPP-ACP: self-etching and universal adhesive systems. Acta Biomat Odontol Scand. 2016; 2: 79-85.

[17] Vaidyanathan T, Vaidyanathan J. Recent advances in the theory and mechanism of adhesive resin bonding to dentin: a critical review. Journal of Biomed Mater Res Part B: Applied Biomat. 2009; 88: 558-578.

[18] Yoshida Y, Yoshihara K, Nagaoka N, Hayakawa S, Torii Y, Ogawa T, et al. Self-assembled nano-layering at the adhesive interface. J Dent Res. 2012; 91: 376-381.

[19] Sabatini C. Effect of a chlorhexidine-containing adhesive on dentin bond strength stability. Oper Dent. 2013; 38 : 609-617.

[20] Zorba YO, Erdemir A, Ercan E, Eldeniz AU, Kalaycioğlu B, Ulker M. The effects of three different desensitizing agents on the shear bond strength of composite resin bonding agents. J Mechan Behav Biomed Mater. 2010; 3: 399-404.

[21] Çehreli SB, Şar Ç, Polat-Özsoy Ö, Ünver B, Özsoy S. Effects of a fluoride-containing casein phosphopeptideamorphous calcium phosphate complex on the shear bond strength of orthodontic brackets. Europ J Orth. 2011; 34: 193-197.

[22] Tabatabaei MH, Arami S, Khajavi F, Moradi Z. Effect of type of cavity preparation (bur, Er\&58; YAG laser) and restorative materials on prevention of caries lesion. J Dent Med. 2017; 29: 229-236.

[23] Ceballos L, Toledano M, Osorio R, Tay F, Marshall G. Bonding to Er-YAG-laser-treated dentin. J Dent Res. 2002; 81: 119-122.

[24] Poosti M, Ahrari F, Moosavi H, Najjaran H. The effect of fractional CO2 laser irradiation on remineralization of enamel white spot lesions. Lasers Med Sci. 2014; 29: 1349-1355.

[25] Esteves-Oliveira M, Zezell D, Ana P, Yekta S, Lampert F, Eduardo C. Dentine caries inhibition through CO2 laser $(10.6 \mu \mathrm{m})$ irradiation and fluoride application, in vitro. Archiv Oral Biol. 2011; 56: 533-539.

[26] Moosavi H, Nemati-Karimooy A. Effect of casein phosphopeptide-amorphous calcium phosphate and erbium: Yttrium-Aluminium-Garnet laser on shear bond strength to demineralized dentin. Eur J Gen Dent. 2020;9:28-32.

[27] Kucukyilmaz E, Botsali MS, Korkut E, Sener Y, Sari T. Effect of different modes of erbium: yttrium aluminum garnet laser on shear bond strength to dentin. Niger J Clin Pract. 2017; 20: 1277-1282. 